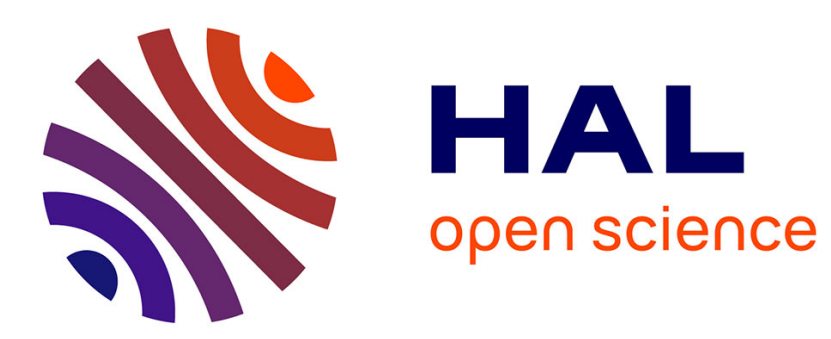

\title{
Micromechanical Fatigue Visco-Damage Model for Short Glass Fiber Reinforced Polyamide-66
}

\author{
Nicolas Despringre, Yves Chemisky, Gilles Robert, Fodil Meraghni
}

\section{To cite this version:}

Nicolas Despringre, Yves Chemisky, Gilles Robert, Fodil Meraghni. Micromechanical Fatigue ViscoDamage Model for Short Glass Fiber Reinforced Polyamide-66. TMS Middle East-Mediterranean Materials Congress on Energy and Infrastructure Systems (MEMA 2015), Jan 2015, Doha, Qatar. pp.451-459, 10.1002/9781119090427.ch48 . hal-01207175

\section{HAL Id: hal-01207175 \\ https://hal.science/hal-01207175}

Submitted on 16 Feb 2017

HAL is a multi-disciplinary open access archive for the deposit and dissemination of scientific research documents, whether they are published or not. The documents may come from teaching and research institutions in France or abroad, or from public or private research centers.
L'archive ouverte pluridisciplinaire HAL, est destinée au dépôt et à la diffusion de documents scientifiques de niveau recherche, publiés ou non, émanant des établissements d'enseignement et de recherche français ou étrangers, des laboratoires publics ou privés. 


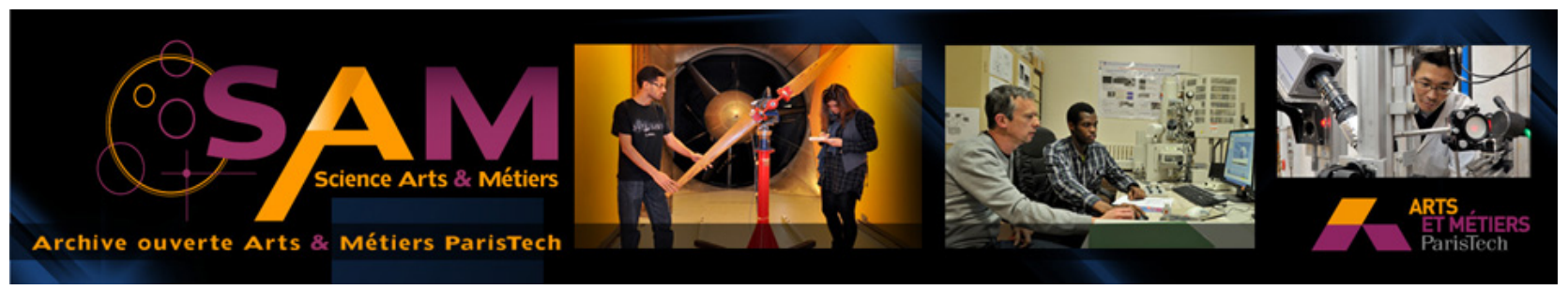

Science Arts \& Métiers (SAM)

is an open access repository that collects the work of Arts et Métiers ParisTech researchers and makes it freely available over the web where possible.

This is an author-deposited version published in: http://sam.ensam.eu Handle ID: .http://hdl.handle.net/null

\section{To cite this version :}

Nicolas DESPRINGRE, Yves CHEMISKY, Gilles ROBERT, Fodil MERAGHNI - Micromechanical Fatigue Visco-Damage Model for Short Glass Fiber Reinforced Polyamide-66 - 2015 


\title{
Micromechanical Fatigue Visco-Damage Model for Short Glass Fiber Reinforced Polyamide-66
}

\author{
Nicolas Despringre; Yves Chemisky; Gilles Robert; Fodil Meraghni
}

${ }^{1}$ Arts et Métiers ParisTech, LEM3 - UMR CNRS 7239 ;

24 rue Augustin Fresnel; Metz Technopôle 57078, France

Solvay Engineering Plastics; Avenue Ramboz BP 64; Saint-Fons 69192, France

Keywords: Polymer-matrix composites, Short glass fiber, Multi-scale modeling, Viscoelastic-

Damage behavior

\begin{abstract}
This work presents a micromechanical fatigue damage model developed for short glass fiber reinforced PA66. It has been developed to predict the high cycle fatigue behavior of PA66/GF30. The model is based on an extended Mori-Tanaka method which includes coated inclusions, matrix viscoelasticity and the evolution of micro-scale damage. The developed model accounts for the nonlinear matrix viscoelasticity and the reinforcement orientation. The description of the damage processes is based on the experimental investigation of damage mechanisms previously performed through in-situ SEM tests and X-ray micro-computed tomography observations. Damage chronologies have been proposed involving three different processes: interface debonding/coating, matrix micro-cracking and fiber breakages. Their occurrence strongly depends on the microstructure and the relative humidity. Each damage mechanism is introduced through an evolution law coupled to local stress fields. The developed model is implemented using a UMAT subroutine. Its experimental validation is achieved under stress or strain controlled fatigue tests.
\end{abstract}

\section{Introduction}

Reinforced thermoplastic structures are increasingly used in the automotive industry. They are especially appreciated for their high strength to weight ratio, thermomechanical performances and their ability to be injection molded. However, the behavior of polyamide-66/short glass fiber $30 \mathrm{wt} \%$ composite (PA66/GF30) is strongly dependent on several coupled effects: complex damage mechanisms, viscous rheology of the matrix, environmental conditions, injection molding microstructure and loading path. Therefore the design of structural parts for high cycle fatigue applications requires advanced modeling tools that accounts for these coupled effects.

Damage mechanisms have previously been investigated by the authors $[1,2]$ and by Cosmi and Bernasconi [5], using in-situ SEM tests and X-ray micro-computed tomography $(\mu \mathrm{CT})$ observations. A damage scenario has been established, depending on the sample relative humidity. Four damage mechanisms occur through fatigue life, at frequencies lower than $5 \mathrm{~Hz}$ : fiber breakage, matrix microcracking, interfacial debonding between fibers and matrix, and matrix deformation bands. Interfacial debonding and related microcracks are proved to be the main process governing the overall damage evolution.

Phenomenological approaches have been frequently adopted to simulate the cyclic behavior of PA66/GF30 composite structures. Recently, a constitutive model has been developed by Launay et al. $[14,15]$ to take into account the elasto-viscoplatic nature of polyamide matrix reinforced by glass fibers. This model does not take into account the evolution of damage. On the other hand, 
the model by Nouri et al. [19] has been developed to account for the evolution of anisotropic damage, but does not take into account material microstructure. Micromechanical models have been developed to account for it in terms of reinforcement shape and spatial distributions. Doghri et al. [7] have developed a multiscale mean-field homogenization method to determine the effective properties of an elasto-vsiscoplastic matrix reinforced with elastic fibers, while $\mathrm{Wu}$ et al. [20] have developed a model that account for the degradation of the material using a gradientenhanced damage model. For short glass fiber reinforced polyamide composites, damage mechanisms are strongly dependent on the material microstructure as well as hygrothermal conditions [1]. Such local damage mechanisms that depend on micromechanical fields need to be included in a multi-scale model to analyze the effect of the material microstructure on the fatigue life. To this aim, a micromechanical model is developed, using an incremental Mori-Tanaka homogenization scheme [18]. It takes into account the non-linear nature of the matrix behavior and the local damage mechanisms. The constitutive response of each phase is based on a dedicated behavior law, and can thus be altered via specific damage mechanisms. The developed constitutive model is implemented into the finite element code Abaqus using a User MATerial subroutine.

In this paper, Section 2 presents the multi-scale model, with a description of the homogenization method and the model adopted to describe the evolution of local damage mechanisms. Section 3 presents the evolution of mechanical fields in a composite material subjected to cyclic loading, with an emphasis on the evolution of local damage.

\section{Multiscale modeling}

\section{$\underline{\text { Homogenization }}$}

Due to the injection molding process, the fiber orientation is not homogeneous within a sample. For the purpose of modeling, the orientation distribution is represented by $\mathrm{N}$ orientation intervals. The representative volume element (RVE) thus consists of the matrix, voids generated by matrix microcracks, $\mathrm{N}$ oriented fibers and $\mathrm{N}$ coating of these fibers, which are assumed to be ellipsoidal. It is worth noting that fiber breakage will introduce two new oriented phases: broken fibers and subsequently coating of broken fibers. Figure 1 shows the RVE evolution in accordance with the previously identified damage mechanisms [1,2]. Furthermore, the fiber volume fraction for each orientation is estimated via Simpson's numerical integration of the experimental orientation density functions (ODF). The next step is to identify the behavior of each phase prior to integrating the damage mechanisms.

The macroscopic effective behavior is computed using the Mori-Tanaka scheme [18]. This method has been extensively used by many authors to obtain the effective behavior of composite materials $[6,9,11,15]$. The Eshelby tensor has been numerically evaluated by the method defined by Lagoudas and Gavazzi [8]. This accounts for the anisotropic nature of the nonlinear tangent modulus of the phases. The computed effective modulus of the homogenized material is recalled equation (1). This homogenization is here adapted to take into account the matrix nonlinear rheology, the composite microstructure and the damage evolution including fiber breakage, matrix microcracking and interfacial debonding. The latter is modeled owing to a coating phase around the fiber, as explained in section 2.3. To take into account all the coupled effects, the loading path is divided into time increments leading hence to an incremental Mori-Tanaka scheme. 


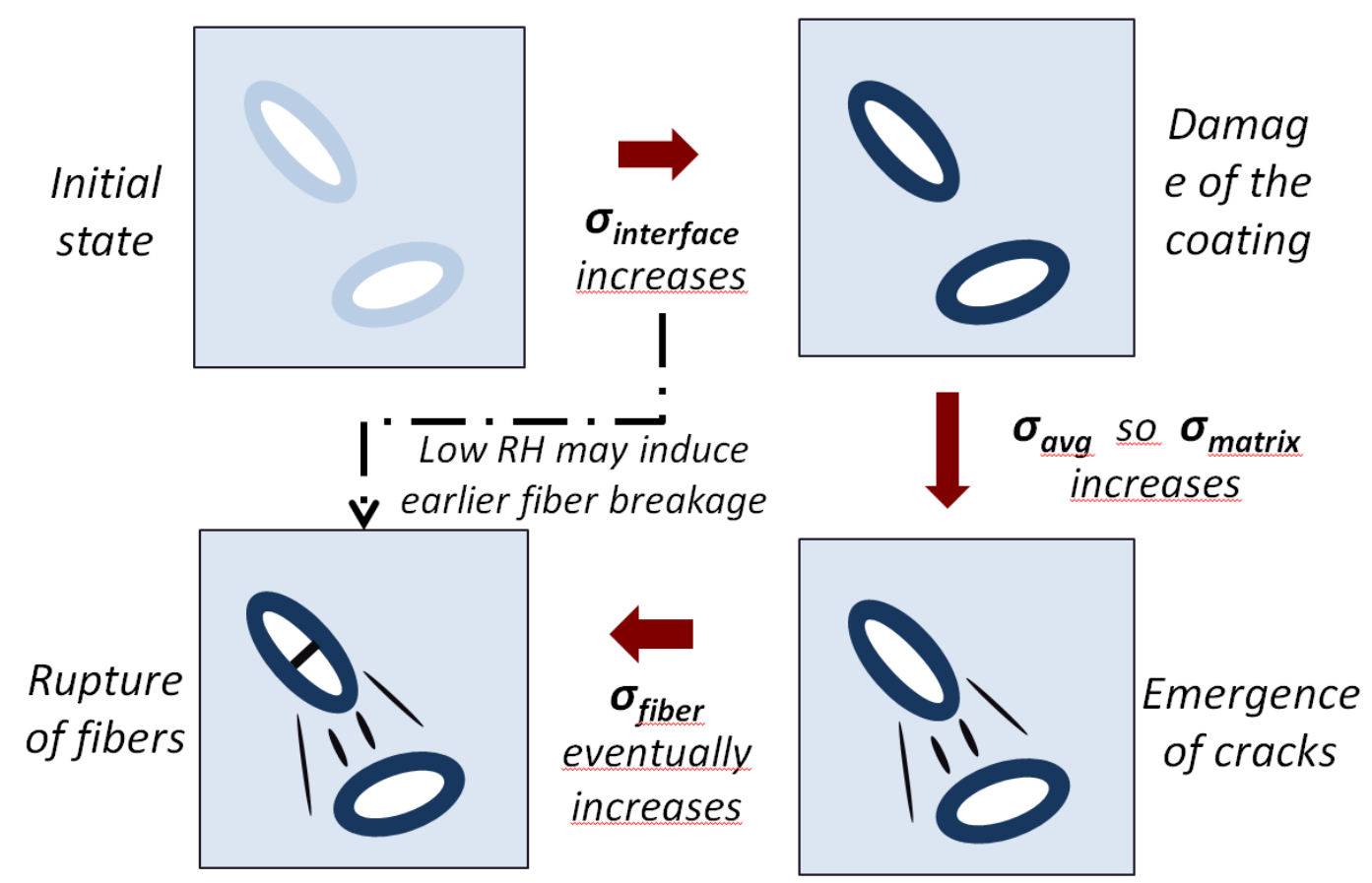

Figure 1. Schematic damage scenario based on experimental observations $[1,2]$ towards modeling

With $\mathrm{r}$ a phase, $\mathrm{cr}$ its volume fraction $\mathrm{Lr}$ its stiffness tensor. Ar is the strain localization fourth order tensor related to phase $r$ and Leff the effective modulus of the homogeneous medium. Ar are computed according to the micromechanical method, i.e. Mori-Tanaka. They are then modified to take into account coated reinforcements. Cherkaoui et al. [4] proposed an approach leading to specific localization equations for coated inclusions. This aspect has been validated with the analytical approach of coated spherical inclusions by Hervé and Zaoui [10].

\section{Constitutive law of the phases}

Voids are assumed to be linear isotropic elastic, with null Young's modulus and Poisson's ratio equal to 0.5. Fibers are assumed to follow the same law, and are identified through their Euler angles, aspect ratio, Young modulus and Poisson's ratio.

DMTA analysis has shown that the polyamide 66 matrix response is viscoelastic. The Cole-Cole diagram from Figure 2 shows several phase transitions. Only the first peak, corresponding to the glass transition, is of practical interest for engineering application due to the related range of temperature. Inverse methods such as genetic algorithm are applied to fit the experimental curves of the Cole-Cole diagram, with different viscoelastic models. A comparative study of Maxwell, generalized Maxwell, Zener, generalized Zener and Havrilak-Negami models proves that the generalized Zener is best suited for matrix viscoelasticity; especially to model the material around the glass transition temperature. This is the main configuration for automotive component applications. 


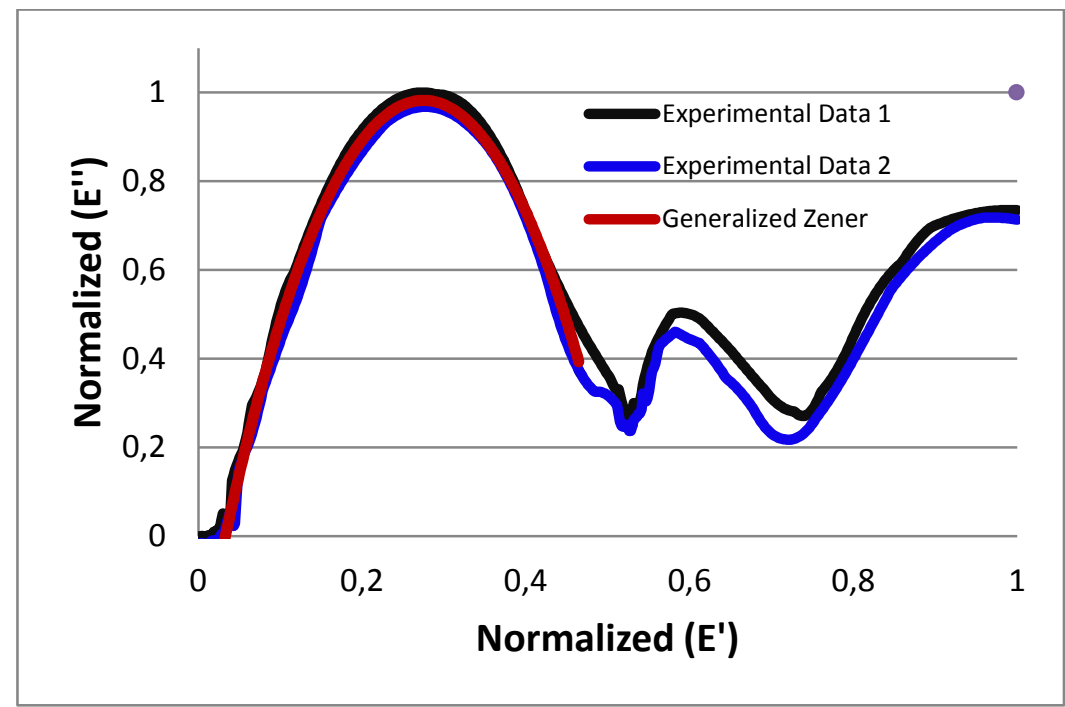

Figure 2. Cole-Cole diagram of the normalized matrix tensile modulus. Two experimental curves were obtained from DMTA experiments and are fitted with the same parameter set of generalized Zener model.

In the proposed model, a simple 3D Zener formulation is implemented. The parameters of this viscoelastic model should therefore depend on the conditions of temperature and relative humidity.

\section{$\underline{\text { Damage mechanisms }}$}

As specified in introduction, damage mechanisms have been studied by the authors [1,2] and by Cosmi and Bernasconi [5]. The retained damage scenario includes three mechanisms: fibermatrix interfacial debonding, fiber breakage and matrix microcracking. Even if they are all occurring at a microscale level, there exists a scale difference between the mechanisms. Indeed the matrix microcracking and the fiber breakage occur at fiber scale, while coating degradation via interfacial debonding occurs at a relative smaller scale. This justifies the specific use of a continuous damage mechanics for the coating related damage, as stated by several authors $[3,13]$. Therefore the three damage mechanisms should be separately implemented.

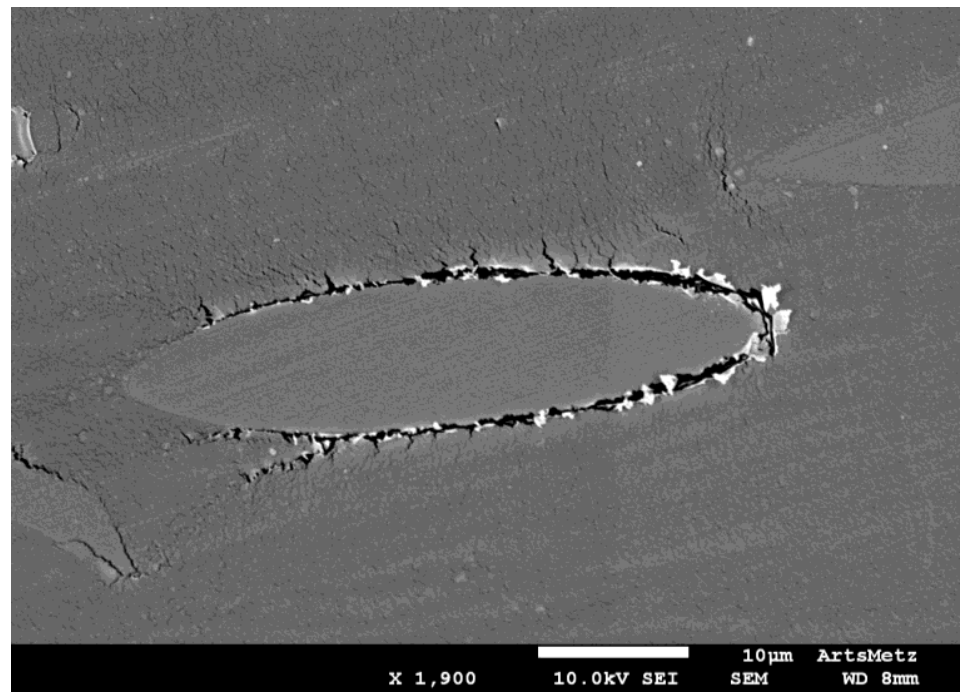

Figure 3. In-situ SEM observation of a PA66/GF30 sample subjected to flexural load. 
The damage evolution is mainly governed by the interfacial debonding, which also generates microcracks in the surrounding matrix (coating). Each fiber is thus embedded into a matrix coating, whose damage consists of matrix microcracking and fiber-matrix debonding. This assumption agrees well with in-situ SEM and $\mu \mathrm{CT}$ observations [2] as shown in Figure 3. The coating degradation is ensured by a stiffness reduction, which comes from an interfacial damage criterion. A rupture criterion of the fiber/coating interface has thus to be defined and developed into a damage criterion. This part is partially based on the work by Jendli et al. [11]. The local failure criterion is set as follows:

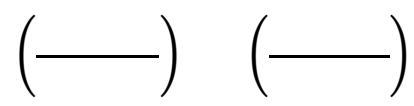

$\sigma_{\mathrm{N}}$ is the normal stress and $\tau$ is the shear stress at the interface. orupture and $\tau$ rupture are respectively the maximum normal and shear stress prior to interfacial debonding. The idea is now to use a normal distribution based on this criterion to determine the coating damage for lower values of $\sigma_{N}$ and $\tau$. Two more parameters have to be set: the shape parameter $\alpha$ and the damage threshold $\varepsilon$ (between 0 and 1). The latter adjusts the mean and the standard deviation of the normal distribution to have $99 \%$ damage along the rupture criterion. Moreover, due to the incremental Mori-Tanaka approach, the damage rate has to be computed. Therefore, the time normalization is then required. It depends on the damage $\mathrm{d}$ and the time increment $\Delta \mathrm{t}$. The probabilisation of this criterion can then be formulated as:

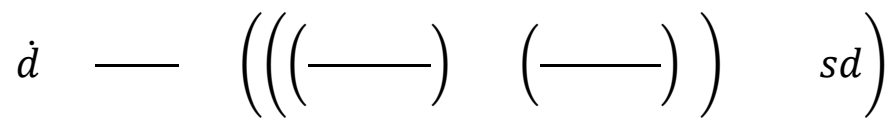

With $\mathrm{N}$ the cumulative distribution function of the normal law with the mean value $\mathrm{m}$ and the standard deviation $s d$, such as:

$s d_{0}$ is the standard deviation which allows to reach $\approx 99 \%$ damage on the rupture criterion for $\varepsilon=0$.

A second normalization due to the specificity of normal distributions is necessary. Indeed, the density function has strictly positive values on $[-\infty ;+\infty]$. This leads to equation (4) illustrated in Figure 4 . The coating tangent modulus linearly decreases with damage as stated by equation (5).

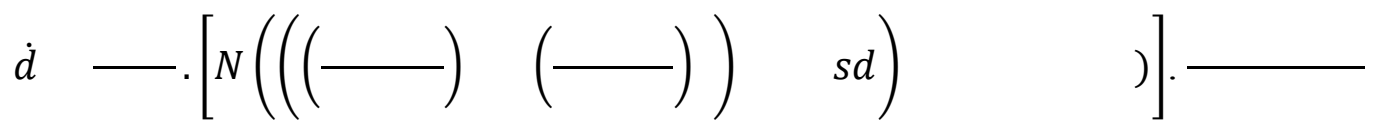

The coating damage is based on interfacial stress field, which is computed using the local fiber stress as given by Meraghni et al. [16]. The damage rate is evaluated all around the ellipsoid, using 2 integration angles. The computed maximum value is kept to estimate the damage increment inside the coating and thus the tangent modulus decrease. 


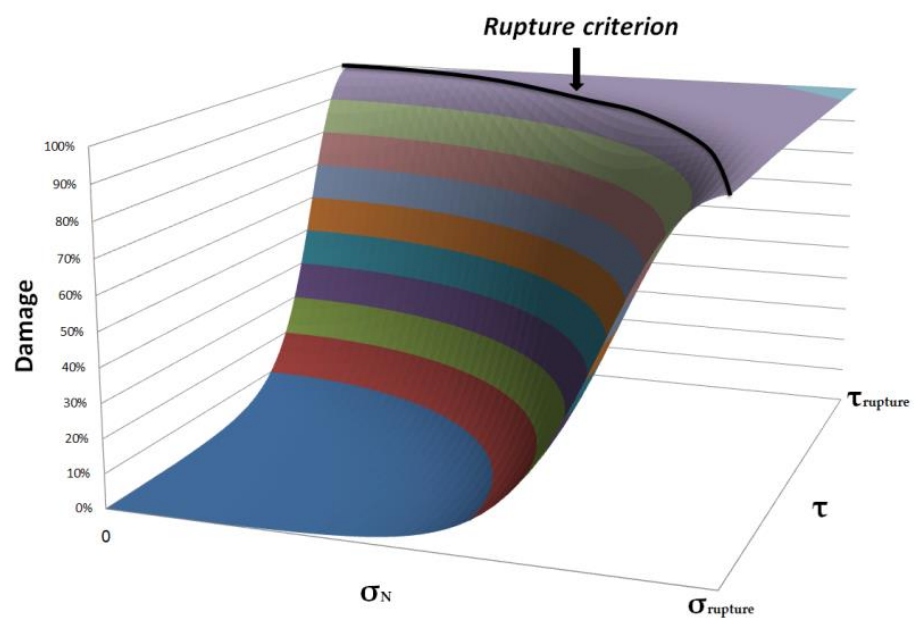

Figure 4. Iso-damaged surfaces given by the interfacial damage law.

Fiber breakage was also modeled. When a fiber breaks, the volume fraction of fiber and its coating decrease while the one of broken fiber and its related coating increase accordingly. The damage law is based on an extended statistical Weibull law to compute damage rate. The trend is strictly designed from a phenomenological point of view and is based on Desrumaux and Meraghni works $[6,16]$. Experimental observations show a few occurrence of fiber breakage for low water content, and only at an early stage of fatigue life. The final equation contains 4 parameters:

$$
\left(\frac{1-d}{}\right) \cdot\left(\begin{array}{ll}
1 & -(-
\end{array}\right)
$$

$m$ is the shape factor, $\sigma_{0}$ is a stress threshold, $\gamma$ and $\delta$ are the damage saturation parameters. This allows representing curves like the one in Figure 5a.
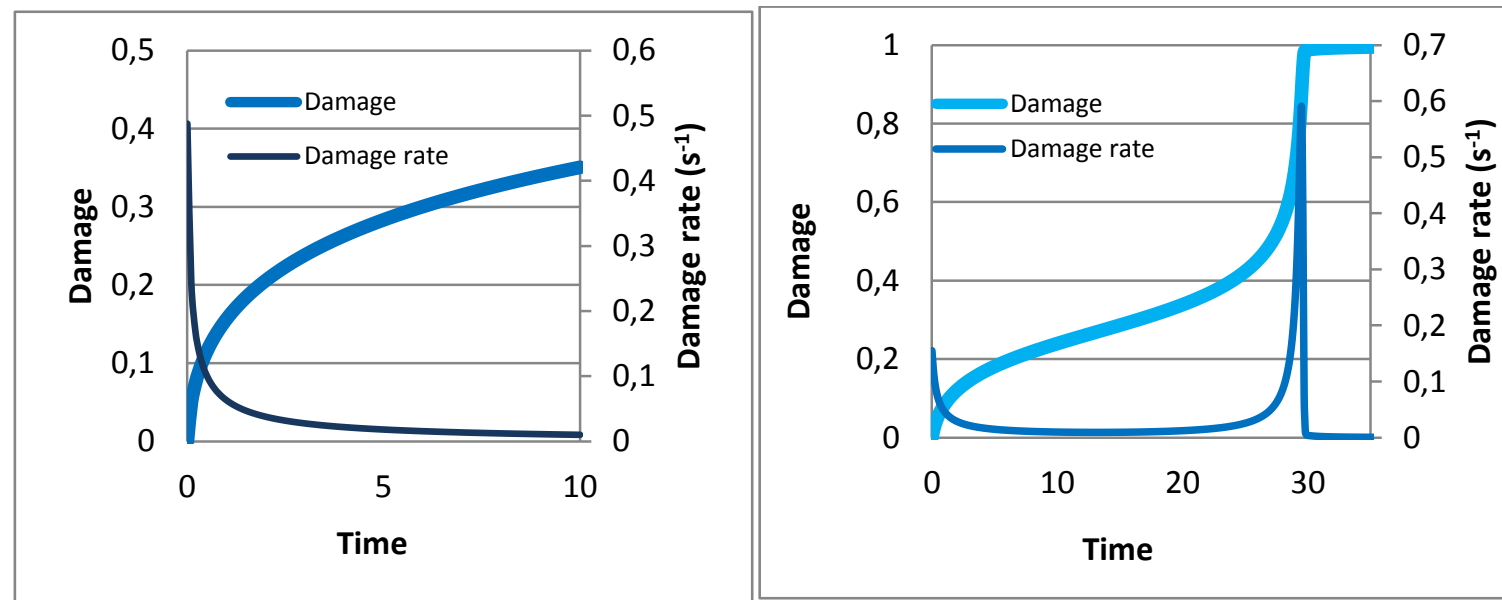

Figure 5. Implemented damage laws for a. fiber breakage and b. matrix microcracking.

As far as matrix microcracks are concerned and from a phenomenological point of view, the mechanisms are very similar to the fiber breakage until late fatigue life. Then the cracks start to coalesce and grow rapidly. So, after the previous saturation step, there is a third step where 
damage rate increase faster with damage/stress until rupture. This is ensured by two new parameters $\alpha$ and $\beta$, which govern respectively the damage threshold that will initiate this crack coalescence and the growing speed of the damage rate until rupture. Matrix volume fraction will decrease consequently. This will increase the void content according to the related damage law. The Figure 4b illustrates this new damage law, whose equation is:

$$
\dot{d}=\left(\frac{1-d}{\Delta t}\right) \cdot\left[\left(1-e^{-\left(\frac{\sigma_{e q}}{(1+\gamma \cdot d)^{\delta} . \sigma_{0}}\right)^{m}}\right)+\left(e^{\left(\frac{\sigma_{e q}}{\sigma_{0}} * \frac{e^{\alpha . d}-1}{e^{\beta(1-d)}}\right)^{m}}-1\right)\right]
$$

\section{Results}

The whole simulation requires several microstructure parameters: number of considered phase and their related orientation and contents. Each phase, matrix excepted, is ellipsoidal and requires the three ellipsoid half-axes required for the Eshelby tensor estimation. The phase behavior and damage laws also have their own parameters.
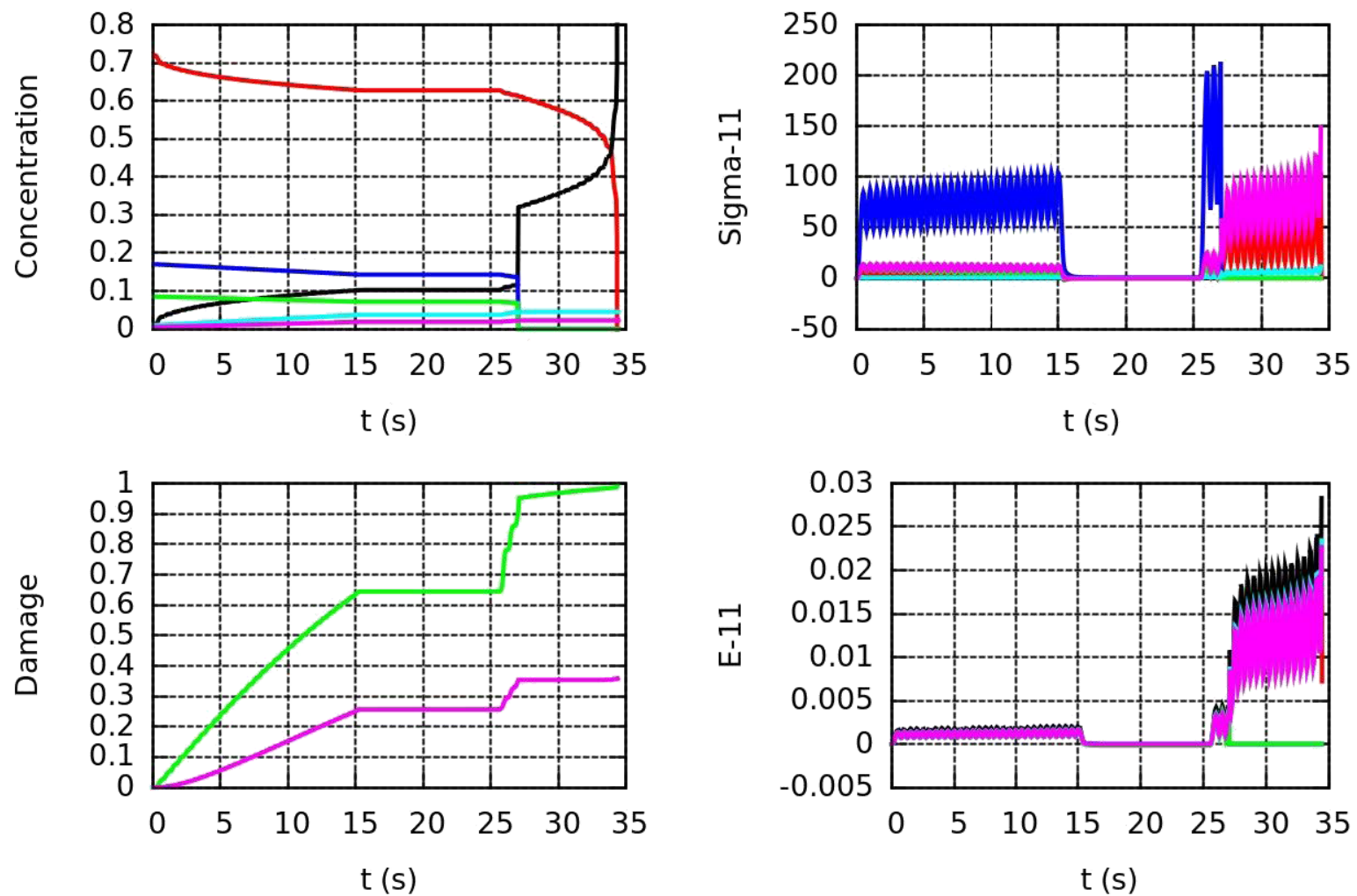

Figure 6. Simulation results with the following color code; Red: Matrix, Black: Voids, Blue: Fibers, Teal: Broken fibers, Green: Coating, Pink: Coating of broken fibers. a. Volume fraction of the 6 phases. b. First component of the local stress tensor for the 6 phases. c. Damage inside both coatings. d. First component of the local strain tensor for the 6 phases.

The model is designed to capture the physical occurring effects for every type of loading path. Arbitrary parameters are chosen to illustrate the model capabilities under uniaxial stress controlled multi-block fatigue loading. For sake of simplicity, one orientation family is considered and set to longitudinal according to the load direction. The aspect ratio is the same for 
fibers and coating and is equal to 100. Results are presented in Figure 6. It is shown that matrix and fiber volume fractions are slowly decreasing in early fatigue life. This is due to matrix microcracking and fiber breakage. Coating damage simultaneously increases during fatigue until it reaches a critic value, here arbitrary set to $90 \%$. Prior to this damage threshold, it can be noticed that the local stress of every other phases increase to account for the coating stress diminution. Beyond this point, the coating is assumed to be damaged and considered as a void, and the same goes to the related fiber. Their local stress and strain fields are therefore reduced to 0 . The remaining phases, especially the matrix, will support the full RVE stress. Microcracks thus tend to coalesce leading to void accumulation until RVE rupture.

\section{Conclusion}

The developed multiscale model is strongly physically based as it is designed to capture the damage mechanisms observed by in-situ SEM test and by $\mu \mathrm{CT}$ tomography $[1,2,5]$. The damage scenario can be numerically reproduced at the microscale. Model calibration with experimental data is undergoing and should be presented in June. Further work includes the implementation of a generalized Zener behavior law to better catch the matrix viscoelasticity.

\section{References}

[1] M. F. Arif, F. Meraghni, Y. Chemisky, N. Despringre, G. Robert. In situ damage mechanisms investigation of PA66/GF30 composite: Effect of relative humidity. Composites Part B: Engineering, Volume 58: 487-495, 2014

[2] M. F. Arif, N. Saintier, F. Meraghni, J. Fitoussi, Y. Chemisky, G. Robert. Multiscale fatigue damage characterization in short glass fiber reinforced polyamide-66. Composites Part B: Engineering, Volume 61: 55-65, May 2014

[3] J. L. Chaboche. Continuous damage mechanics: A tool to describe phenomena before crack initiation. Nuclear Engineering and Design, Volume 64: 233-247, 1981.

[4] M. Cherkaoui, H. Sabar, M. Berveiller. Elastic composites with coated reinforcements: A micromechanical approach for nonhomothetic topology. International Journal of Engineering Science, Volume 33: 829-843, 1995

[5] F. Cosmi, A. Bernasconi. Micro-CT investigation on fatigue damage evolution in short fibre reinforced polymers. Composites Science and Technology, Volume 79: 70-76, 2013

[6] F. Desrumaux, F. Meraghni, M. L. Benzeggagh. Generalized Mori-Tanaka Scheme to Model Anisotropic Damage Using Numerical Eshelby Tensor. Journal of Composite Materials, Volume 35: 603-624, 2001

[7] I. Doghri, L. Adam, N. Bilger. Mean-field homogenization of elasto-viscoplastic composites based on a general incrementally affine linearization method. International Journal of Plasticity, Volume 26: 219-238, 2010.

[8] A. C. Gavazzi, D. C. Lagoudas. On the numerical evaluation of Eshelby's tensor and its application to elastoplastic fibrous composites. Computational Mechanics, Volume 7: 13, 1990 
[9] D. C. Lagoudas, A. C. Gavazzi, H. Nigam. Elastoplastic behavior of metal matrix composites based on incremental plasticity and the Mori-Tanaka averaging scheme. Computational Mechanics, Volume 8: 193, 1991

[10]E. Hervé, A. Zaoui. n-Layered inclusion-based micromechanical modelling. International Journal of Engineering Science, Volume 31: 1-10, 1993

[11]Z. Jendli, F. Meraghni, J. Fitoussi, D. Baptiste. Multi-scales modelling of dynamic behaviour for discontinuous fibre SMC composites. Composites Science and Technology, Volume 69: 97-103, 2009

[12] S. Kammoun, I. Doghri, L. Adam, G. Robert, L. Delannay. First pseudo-grain failure model for inelastic composites with misaligned short fibers. Composites Part A: Applied Science and Manufacturing, Volume 42: 1892-1902, 2011

[13]D. Krajcinovic. Continuum damage mechanics. Applied Mechanics Reviews, Volume 37: 16, 1984.

[14]A. Launay, M. H. Maitournam, Y. Marco, I. Raoult. Multiaxial fatigue models for short glass fiber reinforced polyamide - Part I: Nonlinear anisotropic constitutive behavior for cyclic response. International Journal of Fatigue, Volume 47: 382-389, 2013

[15]A. Launay, M. H. Maitournam, Y. Marco, I. Raoult. Multiaxial fatigue models for short glass fibre reinforced polyamide. Part II: Fatigue life estimation. International Journal of Fatigue, Volume 47: 390-406, 2013

[16]F. Meraghni, C. J. Blakeman, M. L. Benzeggagh. Effect of interfacial decohesion on stiffness reduction in a random discontinuous-fibre composite containing matrix microcracks. Composites Science and Technology, Volume 56: 541-555, 1996

[17]F. Meraghni, F. Desrumaux, M. L. Benzeggagh. Implementation of a constitutive micromechanical model for damage analysis in glass mat reinforced composite structures. Composites Science and Technology, Volume 62: 2087-2097, 2002

[18] T. Mori, K. Tanaka. Average stress in matrix and average elastic energy of materials with misfitting inclusions. Acta Metall., Volume 21: 571-574, 1973

[19]H. Nouri, F. Meraghni, P. Lory. Fatigue damage model for injection-molded short glass fibre reinforced thermoplastics. International Journal of Fatigue, Volume 31: 934-942, 2009

[20]L. Wu, L. Noels, L. Adam, I. Doghri. A multiscale mean-field homogenization method for fiber-reinforced composites with gradient-enhanced damage models. Computer Methods in Applied Mechanics and Engineering, Volumes 233-236: 164-179, 2012 